\title{
Seven Novel seco-Prezizaane-Type Sesquiterpenes from the Pericarps of Illicium merrillianum
}

\author{
Jian-Mei Huang, ${ }^{a}$ Chun-Shu Yang, ${ }^{a}$ Ren Zhao, ${ }^{b}$ Hironobu Takahashi, ${ }^{c}$ and Yoshiyasu FukuYamA $*, c$ \\ ${ }^{a}$ Faculty of Pharmaceutical Sciences, Beijing University of Chinese Medicine; No. 6 Wangjing Zhonghuannanlu, \\ Chaoyang District, Beijing 100102, China: ${ }^{b}$ Yunnan Chinese Medicine Corporation; Kunming 650031, China: and \\ ${ }^{c}$ Institute of Pharmacognosy, Faculty of Pharmaceutical Sciences, Tokushima Bunri University; Yamashiro-cho, Tokushima \\ 770-8514, Japan. Received September 16, 2003; accepted October 20, 2003
}

Seven new seco-prezizaane-type sesquiterpenes were isolated from the methanol extract of the pericarps of Illicium merrillianum. Their structures were elucidated as 3-deoxypseudoanisatin (1), $2 \beta$-hydroxy-3,6-dedioxypseudoanisatin (2), 8 $\alpha$-hydroxy-10-deoxycyclomerrillianolide (3), 10 $\beta$-hydroxypseudoanisatin (4), 10 $\beta$-hydroxycyclopseudoanisatin (5), 1,6-dihydroxy-3-deoxyminwanensin (6), and 8-deoxymerrilliortholactone (7) by analyses of their spectroscopic data and chemical transformation. Compounds 4 and 5 as well as 6 and 7 coexist as a keto/acetal equilibrated mixture in methanol solution.

Key words Illicium, Illicium merrillianum, seco-prezizaane-type sesquiterpene

The genus Illicium is a rich source of prenylated $\mathrm{C}_{6}-\mathrm{C}_{3}$ compounds, ${ }^{1-3)}$ neolignans ${ }^{4)}$ and seco-prezizaane-type sesquiterpenes. ${ }^{5,6)}$ These compounds belong to unique structural types and occur exclusively in Illicium species and are considered to be characteristic chemical markers of Illicium species. The former two types are usually accumulated in the stem bark, root bark, and leaves. However, most sesquiterpenes tend to be biosynthesized in the fruit. We have continued chemical studies on the pericarps of Illicium merrillianum since 1999. As results, about 36 structurally novel sesquiterpenes have been isolated from this species ${ }^{7-14)}$ and classified into the seco-prezizaane, anislactone, and allo-cedrane types. It is worthy of note that an anislactone-type compound, merrilactone A, isolated from this plant shows interesting neurotrophic activity. ${ }^{14)}$ Thus it has attracted synthetic organic chemists due to its structural complexity and outstanding biological activity. ${ }^{15)}$ Those results inspired us to undertake the systematic studies on I. merrillianum. The methanol extract of I. merrillianum was first separated into fractions $\mathrm{A}-\mathrm{G}$ (see Experimental). The main chemical constituent of fractions $F$ and $G$ was shikimic acid. Fractions A-E were purified by various types of chromatography to afford new compounds, as described in our previous papers. $^{7-14)}$ Our further studies of the residual fractions E, D, and $\mathrm{C}$ led to the isolation of seven new sesquiterpenes $\mathbf{1}-\mathbf{7}$. This paper deals with the isolation and structural elucidation of these new sesquiterpenes.

Compound 1 had the molecular formula $\mathrm{C}_{15} \mathrm{H}_{22} \mathrm{O}_{5}$, as established by high-resolution (HR) FAB-MS at $\mathrm{m} / \mathrm{z} 305.1352$ $[\mathrm{M}+\mathrm{Na}]^{+}$. In its IR spectrum, the absorptions at 3389 and $1728 \mathrm{~cm}^{-1}$ showed the presence of a hydroxyl and a carbonyl group, respectively. The ${ }^{1} \mathrm{H}-\mathrm{NMR}$ spectral data of $\mathbf{1}$ (Table 1) contained signals characteristic of pseudoanisatin $(\mathbf{8}),{ }^{16)} \mathrm{ex}-$ cept for the absence of an oxygenated proton signal at $\delta_{\mathrm{H}}$ $4.80(1 \mathrm{H}, \mathrm{m})$ due to $\mathrm{H}-3 \alpha$ in 8 and the presence of signals for a methylene group at $\delta_{\mathrm{H}} 1.70(\mathrm{ddd}, J=13.5,9.5,3.3 \mathrm{~Hz})$ and $\delta_{\mathrm{H}} 2.60$ (ddd, $J=13.5,11.8,5.5 \mathrm{~Hz}$ ), which were assignable to $\mathrm{H}-3 \beta$ and $\mathrm{H}-3 \alpha$. These structural data showed that $\mathbf{1}$ is pseudoanisatin (8) without a hydroxyl group at the C-3 position. The ${ }^{1} \mathrm{H}-{ }^{1} \mathrm{H}$ correlation spectroscopy $\left({ }^{1} \mathrm{H}-{ }^{1} \mathrm{H}\right.$ COSY $)$, ${ }^{1} \mathrm{H}$-detected heteronuclear multiple-quantum coherence (HMQC), and ${ }^{1} \mathrm{H}$-detected heteronuclear multiple-bond con- nectivity (HMBC) data confirmed the planar structure of $\mathbf{1}$. The relative configurations for chiral centers $\mathrm{C}-1$ and C-6 were determined to be the same $1 R^{*}$ and $6 R^{*}$ as those of 8 by nuclear Overhauser effect spectroscopy (NOESY), in which $\mathrm{CH}_{3}-15$ showed cross-peaks to $\mathrm{H}-10 \alpha$ and $\mathrm{H}-8 \beta$, and $\mathrm{CH}_{3}-12$ showed a cross-peak to $\mathrm{H}-14 \alpha$. Thus 1 was assigned to be $3-$ deoxypseudoanisatin.

Compound 2 had the molecular formula $\mathrm{C}_{15} \mathrm{H}_{22} \mathrm{O}_{5}$, as determined by HR-chemical ionization (CI)-MS data at $\mathrm{m} / \mathrm{z}$ $283.1542[\mathrm{M}+\mathrm{H}]^{+}$, and its IR spectrum displayed absorptions due to hydroxyl groups at 3536 and $3318 \mathrm{~cm}^{-1}$, a lactone moiety at $1718 \mathrm{~cm}^{-1}$, and a carbonyl group at $1698 \mathrm{~cm}^{-1}$. The ${ }^{1} \mathrm{H}-$ and ${ }^{13} \mathrm{C}-\mathrm{NMR}$ spectral data (Table 1) suggested that 2 is 6-deoxypseudoanisatin $(\mathbf{1 1})^{16)}$ bearing a hydroxyl group at the $\mathrm{C}-2$ position. The $\mathrm{H}-2$ signal at $\delta_{\mathrm{H}}$ 4.40 (ddd, $J=8.0,7.4,3.8 \mathrm{~Hz}$ ) showed ${ }^{1} \mathrm{H}-{ }^{1} \mathrm{H}$ COSY crosspeaks to the $\mathrm{H}-1$ signal at $\delta_{\mathrm{H}} 2.59(\mathrm{qd}, J=7.4,7.4 \mathrm{~Hz})$ and the $\mathrm{H}-3$ signal at $\delta_{\mathrm{H}} 2.05(\mathrm{dd}, J=15.1,3.8 \mathrm{~Hz})$ and $\delta_{\mathrm{H}} 2.34$ (dd, $J=15.1,8.0 \mathrm{~Hz}$ ), revealing that a hydroxyl group occurs at the $\mathrm{C}-2$ position in $\mathbf{2}$ instead of the C-3 position in 6-deoxypseudoanisatin (11). The cross-peak between $\delta_{\mathrm{H}} 0.93(\mathrm{H}-$

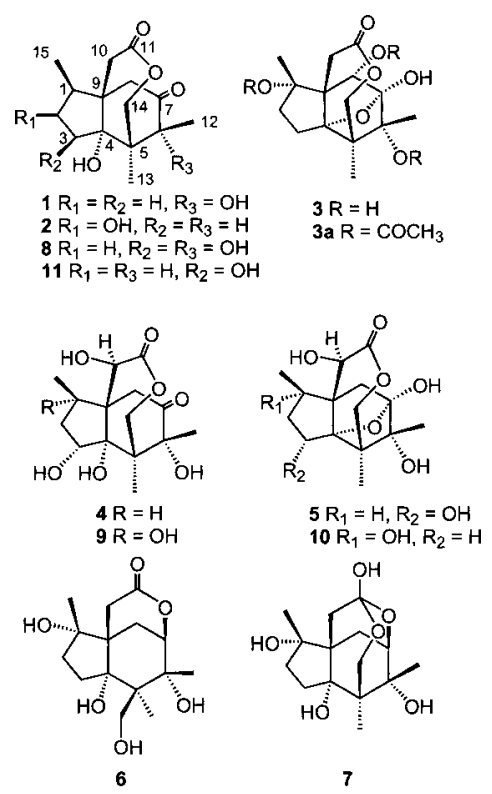

(C) 2004 Pharmaceutical Society of Japan 
Table 1. ${ }^{1} \mathrm{H}$ - and ${ }^{13} \mathrm{C}-\mathrm{NMR}$ Spectral Data of $\mathbf{1}-\mathbf{3}^{\text {a) }}$

\begin{tabular}{|c|c|c|c|c|c|c|}
\hline \multirow{2}{*}{ Position } & \multicolumn{2}{|r|}{$\mathbf{1}^{b)}$} & \multicolumn{2}{|r|}{$\mathbf{2}^{c)}$} & \multicolumn{2}{|r|}{$\mathbf{3}^{d)}$} \\
\hline & $\delta_{\mathrm{C}}$ & $\delta_{\mathrm{H}}$ & $\delta_{\mathrm{C}}$ & $\delta_{\mathrm{H}}$ & $\delta_{\mathrm{C}}$ & $\delta_{\mathrm{H}}$ \\
\hline 1 & 41.6 & 2.55 qdd $(7.0,3.5,1.0)$ & 44.8 & $2.59 \mathrm{qd}(7.4,7.4)$ & 87.7 & \\
\hline $2 \beta$ & 28.7 & 1.35 dddd $(12.0,9.5,5.5,1.0)$ & 70.8 & & 38.8 & $2.01 \mathrm{~m}$ \\
\hline $2 \alpha$ & & 2.07 dddd $(12.0,11.8,3.5,3.3)$ & & 4.40 ddd $(8.0,7.4,3.8)$ & & $2.11 \mathrm{~m}$ \\
\hline $3 \beta$ & 30.3 & 1.70 ddd $(13.5,9.5,3.3)$ & 41.1 & 2.05 dd $(15.1,3.8)$ & 23.3 & $1.98 \mathrm{~m}$ \\
\hline $3 \alpha$ & & 2.60 ddd $(13.5,11.8,5.5)$ & & 2.34 dd $(15.1,8.0)$ & & $2.17 \mathrm{~m}$ \\
\hline 4 & 88.2 & & 82.4 & & 93.9 & \\
\hline 5 & 48.5 & & 46.6 & & 50.6 & \\
\hline 6 & 79.2 & & 47.2 & $2.92 \mathrm{q}(6.9)$ & 77.7 & \\
\hline 7 & 208.2 & & 211.3 & & 108.7 & \\
\hline $8 \beta$ & 36.4 & $2.41 \mathrm{~d}(15.0)$ & 45.8 & $2.39 \mathrm{~d}(15.9)$ & 75.6 & $3.99 \mathrm{~d}(10.2)$ \\
\hline $8 \alpha$ & & $2.65 \mathrm{dd}(15.0,1.9)$ & & $2.69 \mathrm{~d}(15.9,1.9)$ & & \\
\hline 9 & 50.1 & & 48.1 & & 57.7 & \\
\hline $10 \beta$ & 43.2 & $3.00 \mathrm{dd}(15.8,1.9)$ & 36.4 & $2.78 \mathrm{dd}(15.4,1.9)$ & 35.6 & 2.55 brs \\
\hline $10 \alpha$ & & $2.31 \mathrm{~d}(15.8)$ & & $2.49 \mathrm{~d}(15.4)$ & & $3.10 \mathrm{~d}(14.8)$ \\
\hline 11 & 176.4 & & 174.4 & & 171.1 & \\
\hline 12 & 17.7 & $1.30 \mathrm{~s}$ & 7.7 & $1.15 \mathrm{~d}(6.9)$ & 18.3 & $1.36 \mathrm{~s}$ \\
\hline 13 & 14.2 & $1.14 \mathrm{~s}$ & 17.9 & $1.08 \mathrm{~s}$ & 17.0 & $1.01 \mathrm{~s}$ \\
\hline $14 \beta$ & 70.9 & $4.44 \mathrm{~d}(13.9)$ & 68.9 & $4.24 \mathrm{~d}(14.0)$ & 68.7 & $4.06 \mathrm{~d}(14.0)$ \\
\hline $14 \alpha$ & & $3.93 \mathrm{~d}(13.9)$ & & $3.90 \mathrm{~d}(14.0)$ & & $4.04 \mathrm{~d}(14.0)$ \\
\hline 15 & 13.9 & $0.91 \mathrm{~d}(7.0)$ & 7.4 & $0.93 \mathrm{~d}(7.4)$ & 24.2 & $1.47 \mathrm{~s}$ \\
\hline $1-\mathrm{OH}$ & & & & & & $5.13 \mathrm{~s}$ \\
\hline $8-\mathrm{OH}$ & & & & & & $6.05 \mathrm{~d}(10.2)$ \\
\hline 6 or $7-\mathrm{OH}$ & & & & & & $2.30 \mathrm{~s}$ or $4.78 \mathrm{~s}$ \\
\hline
\end{tabular}

a) Coupling constants $(J)$ in $\mathrm{Hz}$ are given in parentheses. b) $\mathrm{In}_{\mathrm{CD}_{3} \mathrm{OD}}$ at $400 \mathrm{MHz}$.

c) In $\mathrm{CDCl}_{3}+\mathrm{CD}_{3} \mathrm{OD}$ at $600 \mathrm{MHz}$. d) In $\mathrm{CDCl}_{3}$ at $600 \mathrm{MHz}$.

$15)$ and $\delta_{\mathrm{C}} 70.8(\mathrm{C}-2)$ in the HMBC spectrum confirmed the $\mathrm{C}-2$ position of the hydroxyl group. Hence $\mathbf{2}$ is 2-hydroxy3,6-dedioxypseudoanisatin. The NOESY correlations between $\mathrm{H}-15$ and $\mathrm{H}-10 \alpha$ as well as $\mathrm{H}-12$ and $\mathrm{H}-14$ were the same as in compound 1. Therefore $\mathrm{CH}_{3}-15$ and $\mathrm{CH}_{3}-12$ took the same $\beta$-configurations as compound 1. Moreover, the hydroxyl group at the C-2 position was determined to have a $\beta$ configuration on the basis of NOESY correlations between $\mathrm{H}-2$ and $\mathrm{H}-3 \alpha$. Thus the structure of $\mathbf{2}$ is $2 \beta$-hydroxy-3,6-dedioxypseudoanisatin.

Compound 3 had a $[\mathrm{M}+\mathrm{Na}]^{+}$ion peak at $m / z 337.1263$ in HR-FAB-MS, corresponding to a molecular formula of $\mathrm{C}_{15} \mathrm{H}_{22} \mathrm{O}_{7}$. Its IR absorptions at 3431 and $1728 \mathrm{~cm}^{-1}$ were due to the presence of hydroxyl groups and a $\delta$-lactone group. The ${ }^{13} \mathrm{C}$-NMR data of $\mathbf{3}$ indicated the presence of a lactone group $\left(\delta_{\mathrm{C}} 171.1\right)$ and an acetal group $\left(\delta_{\mathrm{C}} 108.7\right)$. Additionally, its ${ }^{1} \mathrm{H}-\mathrm{NMR}$ data were very similar to those of $\mathbf{1 0}$ (Table 1). These data suggest that $\mathbf{3}$ has a carbon skeleton like cyclomerrillianolide (10), ${ }^{13)}$ which is the acetal form of merrillianolide (9). Compound $\mathbf{3}$ had three tertiary methyl groups, two isolated methylene groups, one $\mathrm{CH}_{2}-\mathrm{CH}_{2}$ moiety, and an oxymethine group. However, the signal at $\delta_{\mathrm{H}} 3.99$ due to the sole methine existing in 3 was different from $\mathrm{H}-10$ resonating at $\delta_{\mathrm{H}} 5.14$ in $\mathbf{1 0}$. The C-8 position of this oxymethine group was confirmed from the HMBC correlations of $\mathrm{H}-8$ to C-7, C-9, and C-10. Thus 3 is a 3-deoxy-8-hydroxy10-deoxy analogue of 10. Acetylation of 3 gave the triacetylated derivative $\mathbf{3 a}$, in which the hydroxyl groups at C-1, C-6, and $\mathrm{C}-8$ were acetylated but not the $\mathrm{C}-7$ hydroxyl group. This was confirmed by downfield-shifted resonances for $\mathrm{C}-1$, C-6, and H-8. The relative stereochemistry of $\mathbf{3}$ was deduced from the NOESY data as shown in Fig. $1 . \mathrm{CH}_{3}-12$ and $\mathrm{CH}_{3}$ 15 took $\beta$-configurations since they showed NOESY correlations with $\mathrm{H}-14$ and $\mathrm{H}-10$, respectively. Additionally, H-8

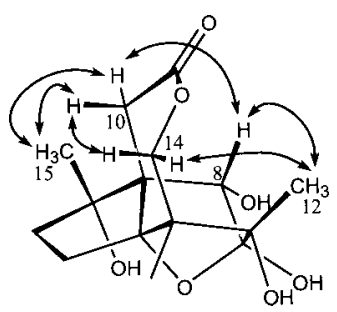

Fig. 1. Representative NOESY Correlations of $\mathbf{3}$

was determined to have a $\beta$-configuration based on the NOESY correlation of H-8 with H-10 and H-12. Hence compound 3 was elucidated to be $8 \alpha$-hydroxy-10-deoxycyclomerrillianolide. Although 10 occurs with 9 as an acetal/keto equilibrated mixture in a methanol solution, 3 exists solely in acetal form.

Compounds $\mathbf{4}$ and $\mathbf{5}$ were obtained as a mixture in the ratio of $3: 2$, deduced from the ${ }^{1} \mathrm{H}-\mathrm{NMR}$ data. The HR-FAB-MS of the mixture showed a molecular ion peak at $\mathrm{m} / \mathrm{z} 337.1281$ $[\mathrm{M}+\mathrm{Na}]^{+}$, corresponding to the molecular formula $\mathrm{C}_{15} \mathrm{H}_{22} \mathrm{O}_{7}$. Its IR spectrum displayed absorption bands at 3358 and $1718 \mathrm{~cm}^{-1}$ due to hydroxyl and carbonyl groups. The well-separated signals (Table 2) in the ${ }^{1} \mathrm{H}-\mathrm{NMR}$ spectrum can be easily assigned to each compound according to the integration of each signal, and thus the ${ }^{13} \mathrm{C}-\mathrm{NMR}$ data (Table 2) were unambiguously assigned on the basis of the HMQC and HMBC correlations. The ${ }^{1} \mathrm{H}-\mathrm{NMR}$ data of 4 were found to be similar to pseudoanisatin (8) except for a newly appearing singlet resonance at $\delta_{\mathrm{H}} 4.27$, corresponding to an oxymethine. The molecular formula of $\mathbf{4}$ also showed one more oxygen atom than 8 . The HMBC correlations of this oxyproton signal $\left(\delta_{\mathrm{H}} 4.27\right)$ to $\mathrm{C}-11, \mathrm{C}-9$, and C-1 disclosed that its position was at $\mathrm{C}-10$. Thus the planar structure 
Table 2. ${ }^{1} \mathrm{H}$ - and ${ }^{13} \mathrm{C}-\mathrm{NMR}$ Spectral Data of $\mathbf{4}$ and $\mathbf{5}^{a)}$

\begin{tabular}{|c|c|c|c|c|}
\hline \multirow{2}{*}{ Position } & \multicolumn{2}{|r|}{4} & \multicolumn{2}{|r|}{5} \\
\hline & $\delta_{\mathrm{C}}$ & $\delta_{\mathrm{H}}$ & $\delta_{\mathrm{C}}$ & $\delta_{\mathrm{H}}$ \\
\hline 1 & 40.2 & $2.64 \mathrm{~m}$ & 43.7 & $2.70 \mathrm{~m}$ \\
\hline $2 \beta$ & 43.4 & $\begin{array}{l}2.04 \text { ddd }(13.2,9.6 \text {, } \\
9.3)\end{array}$ & 44.6 & $\begin{array}{l}2.11 \text { ddd }(13.4,10.9 \text {, } \\
10.0)\end{array}$ \\
\hline $2 \alpha$ & & $\begin{array}{l}1.75 \text { ddd }(13.2,9.0 \text {, } \\
4.2)\end{array}$ & & $\begin{array}{l}1.78 \text { ddd }(13.4,9.8, \\
3.0)\end{array}$ \\
\hline $3 \beta$ & 72.8 & $4.80 \mathrm{dd}(9.3,4.2)$ & 71.6 & $4.40 \mathrm{dd}(10.0,3.0)$ \\
\hline 4 & 87.2 & & 95.0 & \\
\hline 5 & 48.5 & & 52.6 & \\
\hline 6 & 79.6 & & 80.3 & \\
\hline 7 & 207.9 & & 110.4 & \\
\hline $8 \beta$ & 42.9 & $2.18 \mathrm{~d}(16.2)$ & 39.4 & $1.57 \mathrm{~d}(13.7)$ \\
\hline $8 \alpha$ & & $3.07 \mathrm{~d}(16.2)$ & & $1.73 \mathrm{~d}(13.7)$ \\
\hline 9 & 52.9 & & 57.6 & \\
\hline $10 \alpha$ & 77.0 & $4.27 \mathrm{~s}$ & 75.1 & $4.43 \mathrm{~s}$ \\
\hline 11 & 173.7 & & 174.6 & \\
\hline 12 & 17.4 & $1.31 \mathrm{~s}$ & 18.4 & $1.25 \mathrm{~s}$ \\
\hline 13 & 14.7 & $1.21 \mathrm{~s}$ & 17.7 & $1.06 \mathrm{~s}$ \\
\hline $14 \beta$ & 70.2 & $5.05 \mathrm{~d}(13.4)$ & 70.3 & $5.07 \mathrm{~d}(13.4)$ \\
\hline $14 \alpha$ & & $3.90 \mathrm{~d}(13.4)$ & & $3.91 \mathrm{~d}(13.4)$ \\
\hline 15 & 13.7 & $0.95 \mathrm{~d}(7.1)$ & 13.4 & $0.94 \mathrm{~d}(7.1)$ \\
\hline
\end{tabular}

a) In $\mathrm{CD}_{3} \mathrm{OD}$ at $600 \mathrm{MHz}$. Coupling constants $(J)$ in $\mathrm{Hz}$ are given in parentheses.

of 4 was assigned to be 10-hydroxypseudoanisatin.

Compound $\mathbf{5}$ is most likely to be an acetal form of $\mathbf{4}$, since pseudoanisatin-type sesquiterpenes usually occur as a keto/acetal equilibrated mixture. The ${ }^{13} \mathrm{C}$-NMR spectrum showed a downfield-shifted resonance at $\delta_{\mathrm{C}} 95.0$ for C-4 and a resonance at $\delta_{\mathrm{C}} 110.4$ for $\mathrm{C}-7$, disclosing an acetal ring formed between $\mathrm{C}_{4}-\mathrm{OH}$ and the ketone group at $\mathrm{C}-7$. The upfield-shifted signal for $\mathrm{H}-8$ suggested that the adjacent $\mathrm{C}-7$ position turned a carbonyl group in $\mathbf{4}$ into an acetal. This structure was confirmed by analyses of the 2D NMR data.

The relative configuration of $\mathbf{4}$ and $\mathbf{5}$ must be the same, since they readily reach a state of equilibrium. In the NOESY experiment, the observation of a cross-peak of $\mathrm{H}-15 / \mathrm{H}-10$ assigned the $\mathrm{CH}_{3}-15$ as a $\beta$-configuration, and $\mathrm{H}-10$ as an $\alpha$ configuration. The NOESY correlation of $\mathrm{H}-10 / \mathrm{H}-8 \beta$ provided further evidence for the $\alpha$-configuration of $\mathrm{H}-10$. Both $\mathrm{H}-3$ and $\mathrm{CH}_{3}-12$ have $\beta$-configurations as deduced from the NOESY correlations of $\mathrm{H}-3 / \mathrm{H}-14 \beta$ and $\mathrm{H}-12 / \mathrm{H}-14 \alpha$. Thus the structures of $\mathbf{4}$ and $\mathbf{5}$ were elucidated to be $10 \beta$-hydroxypseudoanisatin and $10 \beta$-hydroxy-cyclopseudoanisatin, respectively.

Compounds 6 and 7 were also isolated as an equilibrated mixture in the ratio of $2: 3$. Both had the molecular formula $\mathrm{C}_{15} \mathrm{H}_{24} \mathrm{O}_{6}$ as deduced from a $[\mathrm{M}+\mathrm{H}]^{+}$ion peak at $\mathrm{m} / \mathrm{z}$ 301.1652 in HR-CI-MS. The IR absorption bands at 3291 and $1715 \mathrm{~cm}^{-1}$ indicated the presence of hydroxyl and carbonyl groups. Since all ${ }^{1} \mathrm{H}-\mathrm{NMR}$ signals of the mixture were well separated and the integrations of signals for each compound were different, it was easy to assign all signals to each compound. The ${ }^{1} \mathrm{H}-\mathrm{NMR}$ resonances for 6 (Table 3 ) revealed the presence of two isolated methylene groups $\left(\mathrm{H}_{2}-10, \mathrm{H}_{2}-\right.$ 14), a $\mathrm{CH}_{2}-\mathrm{CH}-\mathrm{O}$ and a $\mathrm{CH}_{2}-\mathrm{CH}_{2}$ fragment, and three tertiary methyl groups, indicating that $\mathbf{6}$ is a minwanensin-type sesquiterpene. In contrast to the NMR signals for minwanensin, ${ }^{17,18)}$ two singlet methyl signal at $\delta_{\mathrm{H}} 1.23$ and 1.25 in 6 showed HMBC correlations to C-1 at $\delta_{\mathrm{C}} 82.7$ and C-6 at $\delta_{\mathrm{C}}$
Table 3. ${ }^{1} \mathrm{H}$ - and ${ }^{13} \mathrm{C}-\mathrm{NMR}$ Spectral Data of $\mathbf{6}$ and $7^{a)}$

\begin{tabular}{|c|c|c|c|c|}
\hline \multirow{2}{*}{ Position } & \multicolumn{2}{|r|}{6} & \multicolumn{2}{|r|}{7} \\
\hline & $\delta_{\mathrm{C}}$ & $\delta_{\mathrm{H}}$ & $\delta_{\mathrm{C}}$ & $\delta_{\mathrm{H}}$ \\
\hline 1 & 82.7 & & 83.3 & \\
\hline $2 \beta, 2 \alpha$ & х 38.6 & $1.88-1.96 \mathrm{~m}$ & 38.2 & $1.95-2.00 \mathrm{~m}$ \\
\hline $3 \beta$ & 31.6 & $\begin{array}{l}2.39 \text { ddd }(14.0,11.8 \\
7.4)\end{array}$ & 30.9 & $\begin{array}{l}2.23 \mathrm{ddd}(14.0,11.0 \\
7.4)\end{array}$ \\
\hline $3 \alpha$ & & $\begin{array}{l}1.85 \text { ddd }(14.0,9.7 \text {, } \\
3.3)\end{array}$ & & $\begin{array}{l}1.79 \text { ddd (14.0, 8.8, } \\
5.2)\end{array}$ \\
\hline 4 & 91.1 & & 82.4 & \\
\hline 5 & 49.7 & & 48.0 & \\
\hline 6 & 76.8 & & 77.9 & \\
\hline 7 & 85.5 & $4.33 \mathrm{dd}(3.4,2.5)$ & 79.4 & $3.78 \mathrm{dd}(3.3,2.7)$ \\
\hline $8 \beta$ & 23.7 & $1.74 \mathrm{dd}(14.5,3.4)$ & 25.1 & $1.48 \mathrm{dd}(13.7,3.3)$ \\
\hline $8 \alpha$ & & $\begin{array}{l}2.65 \text { ddd }(14.5,2.7 \\
2.5)\end{array}$ & & $\begin{array}{l}2.42 \text { ddd }(13.7,2.7 \\
2.5)\end{array}$ \\
\hline 9 & 51.0 & & 50.3 & \\
\hline $10 \beta$ & 38.6 & $2.76 \mathrm{~d}(19.5)$ & 39.9 & $1.66 \mathrm{dd}(14.5,2.5)$ \\
\hline $10 \alpha$ & & $2.46 \mathrm{dd}(19.5,2.7)$ & & $1.88 \mathrm{~d}(14.5)$ \\
\hline 11 & 173.4 & & 111.6 & \\
\hline 12 & 21.8 & $1.25 \mathrm{~s}$ & 21.3 & $1.40 \mathrm{~s}$ \\
\hline 13 & 15.3 & $1.25 \mathrm{~s}$ & 14.8 & $1.01 \mathrm{~s}$ \\
\hline $14 \beta$ & 65.2 & $3.55 \mathrm{~d}(12.2)$ & 68.2 & $3.88 \mathrm{~d}(13.2)$ \\
\hline $14 \alpha$ & & $3.49 \mathrm{~d}(12.2)$ & & $3.45 \mathrm{~d}(13.2)$ \\
\hline 15 & 24.0 & $1.23 \mathrm{~s}$ & 23.0 & $1.16 \mathrm{~s}$ \\
\hline
\end{tabular}

a) In $\mathrm{CD}_{3} \mathrm{OD}$ at $600 \mathrm{MHz}$. Coupling constants $(J)$ in $\mathrm{Hz}$ are given in parentheses.

76.8, respectively, revealing that two hydroxyl groups were attached to the C-1 and C-6 positions. Additionally, there was no hydroxyl group at the $\mathrm{C}-3$ position because the $\mathrm{H}-3$ signal resonated at $\delta_{\mathrm{H}} 1.85(1 \mathrm{H}$, ddd, $J=14.0,9.7,3.3 \mathrm{~Hz})$ and $\delta_{\mathrm{H}} 2.39(1 \mathrm{H}$, ddd, $J=14.0,11.8,7.4 \mathrm{~Hz})$, which were clarified to be coupled with $\mathrm{H}-2$ by ${ }^{1} \mathrm{H}-{ }^{1} \mathrm{H}$ COSY. From these spectral data, 6 was elucidated to be 1,6-dihydroxy-3-deoxyminwanensin. Comparing the ${ }^{13} \mathrm{C}-\mathrm{NMR}$ data of 6 with those of 7, all data appeared in pairs except for $\delta_{\mathrm{C}} 111.6$ in 7 and $\delta_{\mathrm{C}} 173.4$ in $\mathbf{6}$. This implies that 7 is the cyclic ortholactone form of $\mathbf{6}$. The cyclic ring must be formed between $\mathrm{C}_{14^{-}}$ $\mathrm{OH}$ and the carbonyl group at the $\mathrm{C}-11$ positon, since the $\mathrm{H}$ 14 signals showed an HMBC correlation with C-11. According to the NOESY data of 6 and 7, H-15 showed a cross-peak with $\mathrm{H}-10 \alpha$, and both $\mathrm{H}-12$ and $\mathrm{H}-10 \beta$ showed correlations with $\mathrm{H}-14$. Therefore $\mathrm{CH}_{3}-12, \mathrm{CH}_{3}-15$, and $\mathrm{CH}_{2}-14$ all took $\beta$-configurations as minwanensin. Thus compounds 6 and 7 were assigned to be 1,6-dihydroxy-3-deoxyminwanensin and 8-deoxymerrilliortholactone, respectivelty. Compounds 6 and 7 were the first examples involving an equiliblium between a cycloparvifloralone-type and a minwanensin-type compound.

In a previous investigation, some sesquiterpenes were isolated as keto/hemiacetal mixtures. The isolation of an equilibrated mixture of $\mathbf{4}$ and 5 as well as of $\mathbf{6}$ and 7 adds two other examples to this case. To date, these types of mixture have been found to appear in the pseudoanisatin-, ${ }^{19)}$ minwanensin-, and pesudomajucin-subtypes ${ }^{7)}$ of seco-prezizaanetype sesquiterpenes. However, some compounds of these subtypes exist as one form. It is assumed that some structural factors play important roles in the tendency toward the equilibrium.

\section{Experimental}

Melting points were determined on a Yanagimoto micromelting point apparatus. Optical rotations were measured on a Jasco DIP-1000 digital polarimeter. IR spectra were measured on a Jasco FT-IR 5300 infrared spec- 
trophotometer. NMR spectra were recorded on a Varian Unity 600 instrument. Chemical shifts were given as $\delta$ (ppm) with TMS as an internal standard. The MS were recorded on a JEOL AX-500 instrument. Column chromatography was carried out on Kiselgel 60 (70-230 mesh and 230 - 400 mesh), Wakogel C-300, and Sephadex LH-20.

Plant Material The ripe fruits of I. merrillianum A. C. SмITH were collected in Yunnan, China, in September 1998, and voucher specimen 94041 has been deposited in the Herbarium of Beijing University of Chinese Medicine.

Extraction and Isolation The pericarps of I. merrillianum $(3.7 \mathrm{~kg})$ were powdered and extracted with methanol at room temperature to give about $1 \mathrm{~kg}$ of pale yellow extract. The extract $(430 \mathrm{~g})$ was chromatographed on $400 \mathrm{~g}$ of silica gel eluted successively with $\mathrm{CH}_{2} \mathrm{Cl}_{2}, \mathrm{CH}_{2} \mathrm{Cl}_{2}-\mathrm{EtOAc}(9: 1$, $1: 1)$, EtOAc, EtOAc-MeOH $(7: 3)$, and $\mathrm{MeOH}$ to yield seven fractions $(\mathrm{A}-\mathrm{G})$.

Fraction E (3.8 g) was further separated on a sephadex LH-20 column to afford fractions $1-4$. Fraction $2(3 \mathrm{~g})$ was chromatographed on a silica gel column eluted with $n$-hexane-EtOAc $(1: 4)$ to give fractions $5-12$. Further fractionation of fraction $12(447 \mathrm{mg})$ by reverse-phase chromatography afforded fractions $13-15$. Compound $3(1.5 \mathrm{mg})$ and 1,2-dehydro cycloparvifloralone $(6 \mathrm{mg})$ were isolated from fraction $13(84 \mathrm{mg})$ by HPLC [cosmosil $5 \mathrm{C} 18$-AR-II $\left.\phi 4.6 \times 250 \mathrm{~mm}, \mathrm{MeOH}-\mathrm{H}_{2} \mathrm{O}(1: 4), 2 \mathrm{ml} / \mathrm{min}\right]$. Fraction 14 was chromatographed on a silica gel column eluted with $\mathrm{CHCl}_{3}-\mathrm{MeOH}(10: 1)$ to give fractions $16-20$. Compound $3(2 \mathrm{mg})$, the mixture of $\mathbf{6}$ and 7 $(22 \mathrm{mg})$, and pseudomajucin $(5 \mathrm{mg})$ were purified from fraction 17 . Compound $2(4 \mathrm{mg})$ was obtained from fraction 19 by HPLC [cosmosil 5C18AR-II $\left.\phi 4.6 \times 250 \mathrm{~mm}, \mathrm{MeOH}-\mathrm{H}_{2} \mathrm{O}(1: 3), 2 \mathrm{ml} / \mathrm{min}\right]$.

Fraction D (7.0 g) was isolated by chromatography on Sephadex LH-20 to give fractions $21-26$. Fraction 21 was subjected to column chromatography on silica gel eluted with $n$-hexane-EtOAc $(1: 3)$ to afford fractions $27-34$. Fraction 33 was purified by preparative TLC developed with $\mathrm{CHCl}_{3}-\mathrm{MeOH}$ (14:1) to give the mixture of $\mathbf{4}$ and $\mathbf{5}(11 \mathrm{mg})$.

Fraction C (5.4 g) was separated by chromatography on silica gel to afford fractions 35-42 eluted with $n$-hexane-EtOAc (1:1). Fraction $42(365 \mathrm{mg})$ was again subjected to a silica gel column eluted with $\mathrm{CH}_{2} \mathrm{Cl}_{2}-\mathrm{EtOAc}(1: 2)$ to give fractions $43-46$. Compound $1(3 \mathrm{mg})$ was isolated from fraction 45 by HPLC [cosmosil 5C18-AR-II $\phi 4.6 \times 250 \mathrm{~mm}, \mathrm{MeOH}-\mathrm{H}_{2} \mathrm{O}(25: 75)$, $2 \mathrm{ml} / \mathrm{min}$ ]

3-Deoxypseudoanisatin (1): $[\alpha]_{\mathrm{D}}^{18}-40.2^{\circ}(c=0.44, \mathrm{MeOH})$, IR (film) $\mathrm{cm}^{-1}$ : 3389, 1728. ${ }^{1} \mathrm{H}$ - and ${ }^{13} \mathrm{C}-\mathrm{NMR}$ data: see Table 1 . HR-FAB-MS $\mathrm{m} / \mathrm{z}$ : $305.1352[\mathrm{M}+\mathrm{Na}]^{+}$(Calcd for $\mathrm{C}_{15} \mathrm{H}_{22} \mathrm{O}_{5} \mathrm{Na}: 305.1365$ ).

$2 \beta$-Hydroxy-3,6-dedioxypseudoanisatin $\quad(2):[\alpha]_{\mathrm{D}}^{22} \quad-22.0^{\circ} \quad(c=1.08$, $\mathrm{MeOH}$ ), IR (film) $\mathrm{cm}^{-1}: 3536,3318,1718,1698 .{ }^{1} \mathrm{H}-$ and ${ }^{13} \mathrm{C}-\mathrm{NMR}$ data: see Table 1. HR-CI-MS m/z: $283.1542[\mathrm{M}+\mathrm{H}]^{+}\left(\right.$Calcd for $\mathrm{C}_{15} \mathrm{H}_{23} \mathrm{O}_{5}$ : 283.1546).

$8 \alpha$-Hydroxy-10-deoxycyclomerrillianolide (3): $[\alpha]_{\mathrm{D}}^{20}-49.0^{\circ} \quad(c=1.55$, $\mathrm{MeOH}$ ), IR (film) $\mathrm{cm}^{-1}$ : 3431, 1728. ${ }^{1} \mathrm{H}$ - and ${ }^{13} \mathrm{C}-\mathrm{NMR}$ data: see Table 1. HR-FAB-MS $m / z$ : $337.1263[\mathrm{M}+\mathrm{Na}]^{+}$(Calcd for $\mathrm{C}_{15} \mathrm{H}_{22} \mathrm{O}_{7} \mathrm{Na}: 337.1264$ ). EI-MS $m / z: 296$ (3), 179 (100), 161 (52), 133 (36).

Acetylation of $33(1.4 \mathrm{mg})$ was mixed with $50 \mu \mathrm{l}$ of pyridine, $20 \mu \mathrm{l}$ of $\mathrm{Ac}_{2} \mathrm{O}$, and two piceces of DMAP and then allowed to stand at room temperature for $12 \mathrm{~h}$. The product was purified by TLC to give $\mathbf{3 a}(1.7 \mathrm{mg})$. IR (film) $\mathrm{cm}^{-1}: 3485,3341,1746,1730,1715 .{ }^{1} \mathrm{H}-\mathrm{NMR}\left(\mathrm{CDCl}_{3}, 600 \mathrm{MHz}\right) \delta$ : 1.14 (3H, s, H-13), 1.62 (3H, s, H-15), 1.82 (1H, m, H-2), 1.85 (3H, s, H12), $2.05\left(3 \mathrm{H}, \mathrm{s}, \mathrm{COC} \underline{\mathrm{H}}_{3}\right), 2.08(1 \mathrm{H}, \mathrm{m}, \mathrm{H}-3), 2.12\left(3 \mathrm{H}, \mathrm{s}, \mathrm{COC} \underline{\mathrm{H}}_{3}\right), 2.13$ (1H, m, H-3), $2.15\left(3 \mathrm{H}, \mathrm{s}, \mathrm{COCH}_{3}\right), 2.62(1 \mathrm{H}$, br s, H-10), $3.10(1 \mathrm{H}, \mathrm{d}$, $J=14.8 \mathrm{~Hz}, \mathrm{H}-10), 3.21(1 \mathrm{H}$, ddd, $J=15.5,9.7,3.0 \mathrm{~Hz}, \mathrm{H}-2), 4.14(1 \mathrm{H}, \mathrm{d}$, $J=14.2 \mathrm{~Hz}, \mathrm{H}-14), 4.23$ (1H, s, O-7$), 4.32$ (1H, d, $J=14.2 \mathrm{~Hz}, \mathrm{H}-14), 5.28$
$(1 \mathrm{H}, \mathrm{s}, \mathrm{H}-8) .{ }^{13} \mathrm{C}-\mathrm{NMR}\left(\mathrm{CDCl}_{3}, 125 \mathrm{MHz}\right) \delta: 16.7$ (C-12), 19.0 (C-13), 20.6 $\left(\mathrm{COCH}_{3}\right), 21.0(\mathrm{C}-15), 22.2\left(\mathrm{COCH}_{3}\right), 23.1\left(\mathrm{COCH}_{3}\right), 25.1(\mathrm{C}-3), 33.6(\mathrm{C}-$ 2), 35.7 (C-10), 53.0 (C-5), 60.8 (C-9), 69.0 (C-14), 77.1 (C-8), 89.9 (C-6), 92.8 (C-4), 93.6 (C-1), 106.3 (C-7), 169.7 (ㅁ), 170.2 (ㅁ), 170.8 (C-11), 171.1 (므). HR-FAB-MS $m / z$ : $463.1594[\mathrm{M}+\mathrm{Na}]^{+}\left(\mathrm{Calcd}\right.$ for $\mathrm{C}_{21} \mathrm{H}_{28} \mathrm{O}_{10} \mathrm{Na}$ : $463.1581)$

$10 \beta$-Hydroxypseudoanisatin (4) and $10 \beta$-Hydroxycyclopseudoanisatin (5): IR (film) $\mathrm{cm}^{-1}: 3358,1718 .{ }^{1} \mathrm{H}-$ and ${ }^{13} \mathrm{C}-\mathrm{NMR}$ data: see Table 2 . HRFAB-MS $m / z: 337.1281[\mathrm{M}+\mathrm{Na}]^{+}\left(\right.$Calcd for $\mathrm{C}_{15} \mathrm{H}_{22} \mathrm{O}_{7} \mathrm{Na}: 337.1264$ ).

1,6-Dihydroxy-3-deoxyminwanensin (6) and 8-Deoxymerrilliortholactone (7): IR (film) $\mathrm{cm}^{-1}: 3291,1715 .{ }^{1} \mathrm{H}-$ and ${ }^{13} \mathrm{C}-\mathrm{NMR}$ data: see Table 3. HRCI-MS $m / z: 301.1652[\mathrm{M}+\mathrm{H}]^{+}$(Calcd for $\left.\mathrm{C}_{15} \mathrm{H}_{25} \mathrm{O}_{6}: 301.1651\right)$. EI-MS $m / z$ : $301\left(8, \mathrm{M}^{+}\right), 283(33), 265$ (72), 247 (100), 235(78), 217(64), $175(53)$.

Acknowledgments J.-M. Huang would like to acknowledge the HighTech Research Center Fund from the Promotion and Mutual Aid Corporation for Private Schools of Japan for a postdoctoral fellowship. We would like to thank Dr. Masami Tanaka and Miss Yasuko Okamoto for measuring NMR and mass spectra.

\section{References and Notes}

1) Kouno I., Yanagita Y., Shimoto S., Shitomi M., Yang C.-S., Chem. Pharm. Bull., 40, 2461-2464 (1992).

2) Sy L.-K., Saunders R. M., Brown G. D., Phytochemistry, 44, 1099 1108 (1997)

3) Yakushijin K., Sekikawa J., Suzuki R., Morishita T., Furukawa H., Murata H., Chem. Pharm. Bull., 28, 1951-1954 (1980).

4) Kouno I., Iwamoto C., Kameda Y., Tanaka T., Yang C.-S., Chem. Pharm. Bull., 42, 112-114 (1994).

5) Kawano N., Matsuo A., Yakugaku Zasshi, 78, 1220-1223 (1958).

6) Kouno I., Kawano N., J. Chem. Soc. Perkin Trans. I, 1988, 15371539 (1988)

7) Huang J.-M., Yang C.-S., Kondo M., Nakade K., Takahashi H., Takaoka S., Fukuyama Y., Tetrahedron, 58, 6937-6941 (2002).

8) Huang J.-M., Yang C.-S., Fukuyama Y., Chem. Pharm. Bull., 50, $133-136$ (2002).

9) Huang J.-M., Yang C.-S., Tanaka M., Fukuyama Y., Tetrahedron, 57, $4691-4698(2001)$

10) Huang J.-M., Yokoyama R., Yang C.-S., Fukuyama Y., J. Nat. Prod., 64, 428-431 (2001).

11) Huang J.-M., Yang C.-S., Takahashi H., Fukuyama Y., Phytochemistry, $\mathbf{5 5}, 883-886(2000)$

12) Huang J.-M., Fukuyama Y., Yang C.-S., Minami H., Tanaka M., Chem. Pharm. Bull., 48, 657-659 (2000).

13) Huang J.-M., Yang C.-S., Wang H., Wu Q.-M. Wang J.-L., Fukuyama Y., Chem. Pharm. Bull., 47, 1749-1752 (1999).

14) Huang J.-M., Yokoyama R., Yang C.-S., Fukuyama Y., Tetrahedron Lett., 41, 6111-6114 (2000).

15) Birman V. B., Danishefsky S. J., J. Am. Chem. Soc., 124, 2080-2081 (2002).

16) Kouno I., Kawano N., Yang C.-S., J. Chem. Soc. Perkin Trans. I, 1988, 1537-1539 (1988).

17) Yokoyama R., Huang J.-M., Hosoda A., Kino K., Yang, C.-S., Fukuyama Y., J. Nat. Prod., 66, 799-803 (2003).

18) Wang J.-L., Yang C.-S., Yan R.-N., Yao B., Yang X.-B., Zhongguo Yaoxue Zazhi, 29, 693-696 (1994).

19) Schmidt T. J., J. Nat. Prod., 62, 684—687 (1999). 